\title{
A Model for Postdoctoral Education That Promotes Minority and Majority Success in the Biomedical Sciences
}

\author{
Arri Eisen $^{\text {t**} \text { and Douglas C. Eaton }}{ }^{\S}$ \\ ${ }^{\dagger}$ Department of Biology, Institute for the Liberal Arts, ${ }^{\ddagger}$ Center for Ethics, and ${ }^{\circledR}$ Department of \\ Physiology, Emory University, Atlanta, GA 30322
}

\begin{abstract}
How does the United States maintain the highest-quality research and teaching in its professional science workforce and ensure that those in this workforce are effectively trained and representative of national demographics? In the pathway to science careers, the postdoctoral stage is formative, providing the experiences that define the independent work of one's first faculty position. It is also a stage in which underrepresented minorities (URMs) disproportionately lose interest in pursuing academic careers in science and, models suggest, a point at which interventions to increase proportions of URMs in such careers could be most effective. We present a mixed-methods, case study analysis from 17 years of the Fellowships in Research and Science Teaching (FIRST) postdoctoral program, to our knowledge the largest and longest continuously running science postdoctoral program in the United States. We demonstrate that FIRST fellows, in sharp contrast to postdocs overall, are inclusive of URMs (50\% African American; $70 \%$ women) and as or more successful in their fellowships and beyond as a comparison group (measured by publication rate, attainment of employment in academic science careers, and eventual research grant support). Analysis of alumni surveys and focus group discussions reveals that FIRST fellows place highest value on the cohort-driven community and the developmental teaching and research training the program provides.
\end{abstract}

\section{INTRODUCTION}

The challenges of maintaining a robust biomedical research enterprise in the United States are well-documented (Alberts et al., 2014). In addition to the stresses on the system that are often highlighted-decreased funding and thus increased competition, a prolonged pathway to independence as a scientist, and increases in unfunded compliance regulation-the United States still lags in efforts to have the demographics of the population of academic scientists reflect those of the population as a whole (Gibbs et al., 2016; Rybarczyk et al., 2016). Given these challenges, it is perhaps not surprising that interest in academic science careers decreases-especially along ethnic linesduring the science career pathway from college to graduate school to postdoctoral fellowship to academician (Gibbs et al., 2014). Gibbs and others have identified reasons for this, including explicit and implicit bias in the workplace, misalignment of values of underrepresented minorities (URMs) about academic jobs, and the hypercompetitive nature of the science, technology, engineering, and mathematics fields (Gibbs et al., 2014; Layton et al., 2016). The disproportionate attrition in the transition from postdoctoral fellow to the professoriate is independent of how well potential applicants perform in their laboratories, as measured, for example, by publication rates (Gibbs et al., 2014).

Recent systems dynamic modeling has suggested the most important interventions to increase the number of URMs in academic research positions should happen at the postdoctoral stage, increasing the successful transition rate of fellows into entry-level

Cynthia Bauerle, Monitoring Editor Submitted March 14, 2017; Revised August 21 , 2017; Accepted September 19, 2017 CBE Life Sci Educ December 1, 2017 16:ar65 DOI:10.1187/cbe.17-03-0051

*Address correspondence to: Arri Eisen (aeisen(aemory.edu).

(๑) 2017 A. Eisen and D. C. Eaton. CBE-Life Sciences Education @ 2017 The American Society for Cell Biology. This article is distributed by The American Society for Cell Biology under license from the author(s). It is available to the public under an Attribution-Noncommercial-Share Alike 3.0 Unported Creative Commons License (http://creativecommons.org/licenses/ by-nc-sa/3.0)

"ASCB®" and "The American Society for Cell Biology ${ }^{\circledR}$ " are registered trademarks of The American Society for Cell Biology 
academic positions (Gibbs et al., 2016). Although the number of URM PhD graduates in the American science "pipeline" has increased more than ninefold from 1980 to 2013, there has not been a commensurate increase in the number of URMs in assistant professor positions in basic research in medical schoolsand, in fact, this number has decreased somewhat over this time period. In contrast, the rate of increase in majority $\mathrm{PhD}$ graduates in relation to the increase in number of majority scientists has been proportional and roughly the same. The models predict that, in the near future, improving the postdoc-to-professor transition rate is key, as opposed to increasing the pool of URMs in the pipeline or the number of available positions.

The challenge for the scientific community, then, is to develop postdoctoral training that increases the quality and preparedness of everyone entering the academy and other professional science opportunities, while simultaneously identifying and addressing factors that will increase the rate at which URMs remain in academic science. While research training and publication have traditionally been the primary drivers of graduate and postdoctoral experiences in science training, such research-driven experiences, especially for postdoctoral fellows, often lack structured and formal community and support—criteria identified as keys to success, especially for minorities and women, but for all scholars (Brommer and Eisen, 2006; Estrada-Hollenbeck et al., 2011; National Academy of Sciences, National Academy of Engineering, and Institute of Medicine, 2011). In addition, given that the future jobs of these trainees will often involve significant teaching, communication, and mentoring, effective education in these areas would appear to be prudent.

Intentional inclusion of developmental opportunities in graduate and postdoctoral training programs often builds community formally and informally through shared research scholarship and exchange, as well as through shared pedagogical training and experiences, peer and senior mentoring, and professional development activities (Hue et al., 2010; Faupel-Badger et al., 2015; Ross et al., 2016; Rybarczyk et al., 2016). That is, the very nature of these programs tends simultaneously to improve training and to build community. Inclusion of such developmental opportunities should enrich the experience of those in the programs and increase the sustainability of their participation in science in general (Holtzclaw et al., 2005; Estrada-Hollenbeck et al., 2011; Jackson et al., 2016; Layton et al., 2016). An example at the graduate level of such enhanced training intended to develop faculty prepared to address the many and diverse responsibilities of the professoriate is the Preparing Future Faculty program supported by the Council of Graduate Schools, together with the American Association of Colleges and Universities, in nearly 300 institutions (Bashara, 2002). The Initiative to Maximize Student Development (IMSD), funded by the National Institutes of Health (NIH), also provides institutions nationwide with the resources to support graduate (and undergraduate) programs focused specifically on increasing diversity and decreasing attrition of URMs in the science workforce; additionally, IMSD programs provide structured, formal support in a holistic approach to training and career development (Thompson and Campbell, 2013).

At the postdoctoral level, a leader in such structured, developmental training open to all and explicitly engaging URMs is the Institutional Research and Career Development Awards (IRACDA), funded by the National Institute of General Medical Sciences' (NIGMS) Division of Training, Workforce Development, and Diversity at the NIH. There are currently 22 IRACDA programs distributed throughout the United States (NIGMS, 2017). IRACDA programs are partnerships between R1 and minority-serving undergraduate institutions (MSIs). Training in these programs combines a traditional, rigorous research experience with a mentored teaching experience at a partner MSI along with other professional development opportunities.

Given the constraints and limitations of the current science career pathway, it is incumbent upon the scientific community to identify best practices in postdoctoral training in order to focus resources productively and effectively and thus sustain a leading, successful, and inclusive national science enterprise. To accomplish this, and especially given the findings noted earlier suggesting the importance of improving the postdoc-to-professor transition rate among URMs, analysis of postdoctoral development programs is needed to obtain a deeper understanding of best practices. As noted by Rybarczyk et al. (2016), while it is clear that the number of traditional tenure-track jobs is shrinking, it is less clear why young people stay in science and why they leave-the influence of mentors, financial support, motivation, personal values, and math and science skills have all been cited as contributors-and how to best prepare these trainees for both faculty positions and other less traditional careers in science.

FIRST (Fellowships in Research and Science Teaching) is to our knowledge the longest continuously running and largest science postdoctoral training program in the United States. FIRST, an IRACDA program, combines intensive, formal, structured training in teaching and research with professional development, formal and informal community building, and explicit efforts to increase the diversity of the science workforce. In this study, we analyze data from 17 cohorts of FIRST fellows $(n=177)$ to explore and elaborate the following three points: 1) while explicitly not a minority program, FIRST attracts URM PhDs and keeps them in science, therefore increasing the diversity of science in academia and related professions, while positively impacting the MSI program partner institutions; 2) FIRST fellows (both minority and majority), who have intensive training in both research and teaching, perform as well or better than traditional research-only fellows in publishing, obtaining and remaining in research-related employment, and earning research grant support once employed; 3) FIRST fellows' success in these areas may in part be due to the community within their cohort and within FIRST as a whole, a community that emerges as a result of explicit and structured training in teaching and research together.

\section{METHODS}

\section{Description of the Program}

FIRST is an IRACDA program of the NIGMS at the NIH (NIGMS K12 \#GM000680). FIRST is a collaboration among Emory University and the institutions of the Atlanta University Center (AUC): Clark Atlanta University, Morehouse College, Spelman College, and the Morehouse School of Medicine. FIRST fellows perform a traditional 3-year research fellowship with a research mentor, together with additional formal professional opportunities, including a developmental teaching experience. The 
latter begins with a semester-long course in current pedagogies and exploration of the primary literature in teaching and learning, culminating with a "course-within-a-course" taught by the fellows to themselves, incorporating techniques learned, with each class session followed by peer and instructor evaluation (further elaborated in Holtzclaw et al., 2005). After the completion of this course, each fellow selects a teaching mentor at the AUC with whom the fellow develops a program of training and then, for at least one semester, takes a leadership role in teaching a course. FIRST fellows design new courses, renovate old ones, and often present the results of their experiences at national meetings or publish them in the peer-reviewed literature (Holtzclaw et al., 2006; Keen-Rhinehart et al., 2009). Fellows also mentor their peers; have their own research seminar series; have developed a forum for presenting practice job talks; periodically host the annual meeting of all IRACDA programs nationwide; and design, develop, and host other professional development opportunities.

\section{Participants}

FIRST fellows enter the program through an open national application as an annual cohort of six to 10 fellows; because it is a 3-year fellowship, a community of 18-30 FIRST fellows exists at any one time. We are currently accepting our 18th cohort. We recruit fellows at the Annual Biomedical Research Conference for Minority Students and at the Society for Advancement of Chicanos/Hispanics and Native Americans in Science conference, and current FIRST fellows present the program at the education forums of their research conferences. Most of our applicants report that they hear about FIRST at one of these conferences, informally by word of mouth, or through our website. Applications are reviewed by a committee that includes two fellows and faculty representatives from each partner institution. Applicants must have identified a research mentor who has agreed to play that role before being considered for admission. Fellows are then selected based on publication record, teaching experience and insight, and commitment to diversifying the science workforce. In their biomedical research, fellows specialize in any area supported by NIGMS, including genetics, physiology, drug design, biochemistry, evolution and ecology of disease, public health, behavioral sciences, cell biology, and neuroscience. This study analyzes data from 177 fellows in the first 17 cohorts of the program and compares them against two groups: 1) 96 recent National Research Service Awards Institutional Postdoctoral Training Grant (T32) postdoctoral fellows at Emory University and 2) 536 recent T32 NIGMS basic research (PhD) postdoctoral fellows at Emory and other institutions (these other institutions have IRACDA programs and include the University of North Carolina-Chapel Hill [UNC], the University of Pennsylvania [Penn], Tufts University, and the University of Arizona). Alternatively, when data were not available for comparison, we used data collected and published by NIH for T32 fellows nationally (Mantovani et al., 2006).

\section{Data Collection and Analysis}

We used a mixed-methods analysis of the FIRST program as a case study for best practices in postdoctoral education. All data collection and analysis was approved by the Emory Institutional Review Board. Demographic, publication citation, and job placement data for FIRST fellows are all self-reported, confirmed, and stored in a secured database linked to identification by the program administrator.

\section{Publication and Job Placement Data}

We used publication and job placement data to measure the effectiveness of FIRST. These data are obtained annually while fellows are in the program and are confirmed on PubMed. Annual PubMed searches identify publication citations of FIRST alumni. Job placement is monitored and recorded as part of data collection for annual reports submitted to the NIH.

Comparison postdoctoral program data were obtained as de-identified, aggregate data; T32 data were provided by the Emory Office of Postdoctoral Education, and data in the comparison group for other institutions' T32 fellows were provided by IRACDA program directors at those institutions and obtained from publicly available NIH or National Science Foundation (NSF) data.

\section{Publication Rate}

Mean publication rates were determined for FIRST fellows and current T32 fellows at Emory and current and former T32 fellows at institutions with established IRACDA programs (Emory, UNC, Penn, Tufts, and University of Arizona). Only publications from within fellows' postdoctoral training time and only from fellows with between 6 and 60 months of training were included. The distributions of the number of papers published per year are strongly skewed toward small numbers. In fact, the most common occurrence is for a fellow to have zero publications in any given year. This distribution is not Gaussian, but rather is an exponential distribution of frequency of publication events versus number of publications. Such distributions have large standard deviations - the SD is approximately equal to the mean of the distribution. Therefore, traditional $t$ tests are not appropriate to determine differences (Krishnamoorthy and Thomson, 2004).

\section{Survey Data}

Qualitative data were collected to gain insight into how fellows view the program and its impact. Data concerning the impact of FIRST on fellows' careers and the reasons for that impact were collected from an online survey (SurveyMonkey) sent to 147 alumni (all of those who had completed the program or taken jobs by 2014, when the survey was sent out), from whom 46 responses were obtained without any link to identification.

Other qualitative data exploring reasons that fellows initially applied to FIRST and how they currently were experiencing the program (in Fall 2014 and Spring 2016) were obtained from focus groups. Focus groups were composed of three to four fellows who volunteered by responding to an open invitation sent to all the fellows in the program at the time; focus group discussions were carried out by an independent evaluator who asked questions and recorded conversations, none of which were not linked to any participants' identities.

These qualitative data were coded and analyzed by hand by three researchers (A.E. and D.C.E. and then a third independent researcher who knew nothing of FIRST before analysis) separately, to mitigate bias, as described by Merriam and Tisdell (2016). Each researcher independently first separated responses into categories that emerged from participant responses; categories were then consolidated into themes. Distinct portions of 
the same response sometimes fit into different themes. The same themes were identified in analysis of responses from both surveys and focus groups. From this process also emerged, for each researcher, the frequency with which each theme was addressed by participants. Then, for internal consistency, themes were compared among the researchers. The top two themes in both surveys and focus groups-cohort/community support and teaching/pedagogy — were identified as such by all three researchers. Two other themes-research training and career development/gaining employment-were also identified by all three researchers. Two themes-independent funding support and working with MSIs-were grouped together under "other" by one researcher (A.E.), but listed separately by the other two researchers. One researcher (M.M.) identified two additional categories-supportive administration/staff and teaching mentorship-that were merged with cohort/community support and teaching/pedagogy, respectively. As would be expected, given the agreement in the assignment of themes, the frequency with which each theme was addressed was also consistent across the researchers' analyses.

\section{RESULTS}

\section{A More Diverse Workforce}

FIRST attracts a wide variety of applicants, but disproportionately attracts both URM and women postdoctoral fellows and keeps them in science, therefore increasing the diversity of academic and other science professions, while positively impacting our MSI program partner institutions. FIRST and other IRACDA programs are open to any aspiring postdoc interested in teaching and research in science, but FIRST and other IRACDA programs attract a greater percentage of URMs and women than their percentage representation in the overall national postdoctoral pool.

Of the 177 FIRST fellows who are or have been in the program, 50\% are African American, as compared with less than $3 \%$ of all science and engineering postdocs in the United States, and more than $70 \%$ of FIRST fellows are women, as compared with the national level of $41 \%$ (these national levels are a snapshot from 2013 [NSF, 2013], while the data for FIRST include 2000-2016). FIRST fellows contribute significantly to the overall diversity of all postdoctoral fellows at Emory, representing an average of $38 \pm 3 \%$ of all URM Emory postdocs from 2000 to 2014, and in some years more than half of that population (Figure 1). Figure 1 also shows that, before the inception of FIRST, there were very few URM fellows in the sciences at Emory, but the situation has since changed.

Do the URM fellows remain in science when they leave FIRST? Of the 75 URM FIRST alumni, 13 are at research-intensive institutions, 28 are at liberal arts institutions or MSIs, five are in industry, 11 are in government research, and six are in academic or government administrative positions. Twelve are in other positions, including self-employment and working as primary or secondary school instructors. All URM FIRST alumni are employed (note: this does not include six of the 177 fellows who have entered the program since 2000, as two left very early for personal reasons and four cannot currently be located), with $84 \%$ in scientific academic or research and teaching-intensive situations. Below, we further elaborate these data in the greater context of overall FIRST fellows' employment.

To measure the impact of FIRST on our partner MSIs, we examined outcomes from formal and informal interactions

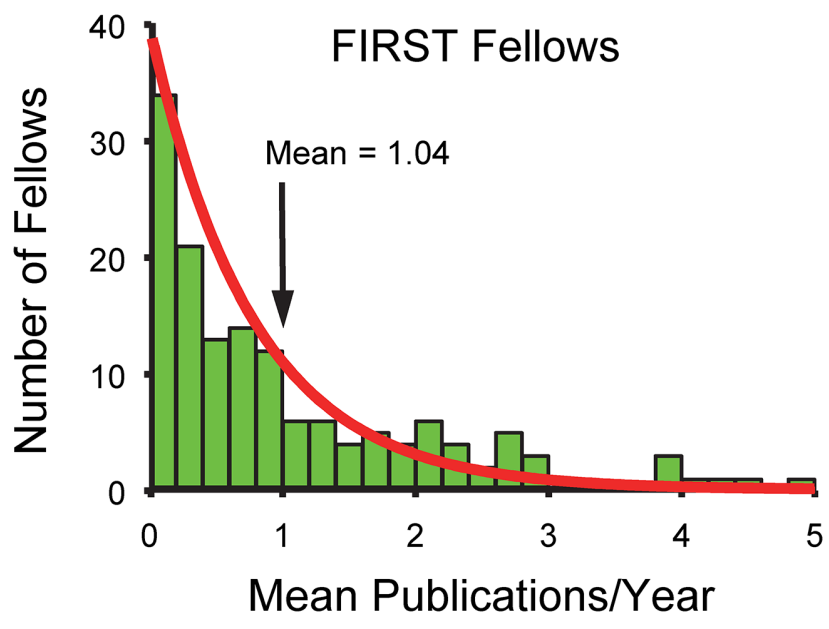

FIGURE 1. Rate of publishing by FIRST fellows. The frequency of postdoctoral publishing is described by a Poisson (exponential) distribution with excess zero events (postdocs who do not publish). For a Poisson distribution, the population mean and variance are equal. Most traditional parametric statistics cannot be used to test hypotheses (but specialized tests to compare means can be used; see Methods).

between fellows and different MSI constituencies (Table 1). We determined the number of courses and labs developed, revised, and taught by FIRST fellows working with MSI Teaching Mentor faculty, MSI undergraduates mentored by FIRST fellows, and FIRST fellows hired by those institutions as faculty members. Thus far, more than 35 new courses and labs have been developed and more than 40 courses and labs have been revised at the MSIs by FIRST fellows. Additionally, 19 MSI undergraduates have been mentored by FIRST postdoctoral fellows in their research laboratories, and FIRST fellows have instituted biannual information sessions at our MSI partners discussing "the ins and outs" of graduate school and how to apply. The number of applications to biomedical graduate schools from partner MSI undergraduates has increased since the inception of FIRST, but a direct connection to FIRST fellows' teaching and other activities has not been investigated. Also, nine peer-reviewed publications in teaching scholarship have been coauthored by MSI teaching mentor faculty and FIRST fellows. Finally, 19 FIRST fellows have thus far been hired as faculty at the MSI partner institutions.

\section{FIRST Fellows Perform at a High Level}

To explore our second point-to see if FIRST fellows, who have intensive training in both research and teaching, perform as well or better than those postdoctoral fellows with training

TABLE 1. Impact of FIRST on partner MSIs, 2000-2016

\begin{tabular}{lc}
\hline Activity & Number \\
\hline New courses and labs developed and taught & $>35$ \\
Existing courses and labs revised & $>40$ \\
$\begin{array}{l}\text { MSI undergraduates mentored by FIRST fellows in } \\
\quad \text { research labs }\end{array}$ & 19 \\
$\begin{array}{l}\text { Peer-reviewed teaching publications coauthored by fellows } \\
\quad \text { and MSI teaching mentors }\end{array}$ & 9 \\
FIRST fellows hired as faculty by partner MSIs & 19 \\
\hline
\end{tabular}


focused on research only-we examined three traditional postdoctoral training outcome measures: publishing rates in peer-reviewed journals, obtaining and remaining in research/ teaching-related employment, and earning research grant support once employed.

One-hundred-and-sixty-eight FIRST fellows with more than 6 months program participation have published 169 papers as first authors, 205 papers as coauthors with their FIRST research mentors, and 210 additional papers with authors other than FIRST mentors. Table 2 shows that the overall publication rate of FIRST fellows exceeds the rate for both comparison groups ( $p=0.027$ for Emory T32 fellows, $p=0.0052$ for T32 fellows from other institutions that host IRACDA programs). The overall publication rates of FIRST majority (Caucasian and Asian) fellows is greater than that of T32 fellows at Emory or other institutions ( $p=0.023$ and $p<0.001$, respectively). The Poisson tests necessary for this analysis-due to the excess of "zero events," the common occurrence of zero or one publication in any given year-are not as strong as tests on normal distributions, so we are careful about claims that FIRST fellows have a greater publication rate than the comparison groups, but FIRST fellows' publication rates are clearly not less than those groups.

\section{Employment}

To test whether FIRST alumni are successful in obtaining and remaining in science research/teaching-related jobs, we compared the employment situations of 145 FIRST alumni with those of T32 fellows in a national database from the NIH Office of Extramural Programs (Mantovani et al., 2006). Figure 2A shows that the distribution of employment is not significantly different (by $\chi^{2}$ analysis), with the exception being the perhaps unsurprising outcome, given the nature of the FIRST program's goals, that more from the comparison group take positions in industry.

One way to investigate success in academic science is to measure how long after gaining employment it takes to earn extramural funds and, further, to explore the nature of that funding. To that end, we examined the extent to which FIRST alumni have competed successfully for grant support compared with their T32 peers. We have no direct information about the performance of T32 alumni at either Emory or other IRACDA institutions, so we turned to historical data collected by NIH in their evaluation of T32 programs (Mantovani et al., 2006). Specifically, these data provide information about the average time after completing T32 postdoctoral support before a fellow receives some sort of extramural support. The type of research support considered in these NIH statistics includes traditional R01 grants, all R awards (mostly NIH Small Grants [R03], AREA Grants [R15], and Exploratory/Developmental Grants [R21]), and Career Development (K) awards. The caveat in these data are that they represent only those individuals who have applied and been awarded a grant. Other data in the NIH report suggest that the success rate for application is $\sim 33 \%$ (Mantovani et al., 2006). Nonetheless, we presumed that all of the FIRST fellows in academic environments would apply for some grant and continue to apply until they received an award. On the basis of this assumption, we would expect that, collectively, there should be the same number of grants to FIRST fellows as to T32 fellows.

Figure 3 presents the relevant information from the $\mathrm{NIH}$ report, the distribution of times to funding for FIRST alumni after their fellowship, and the expectation for grants based on

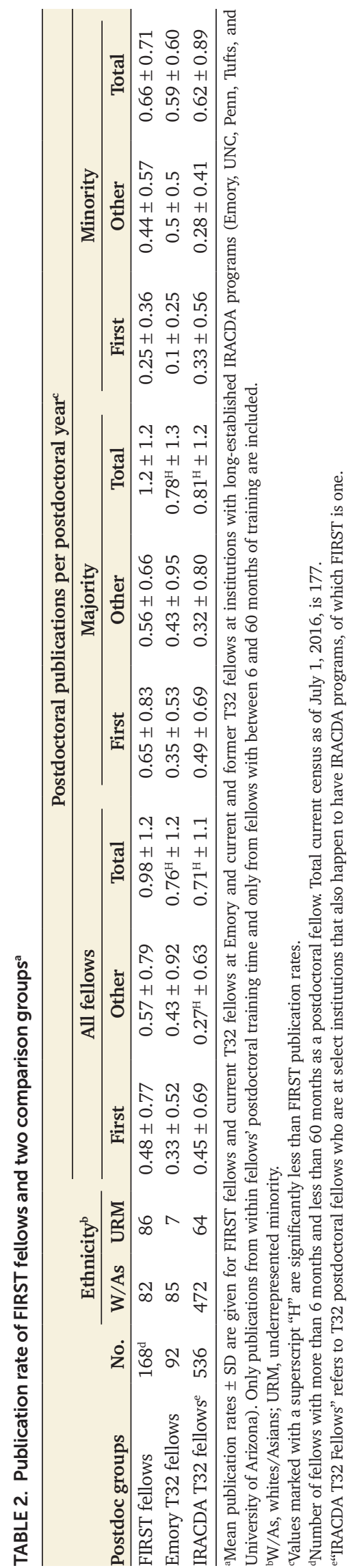


A
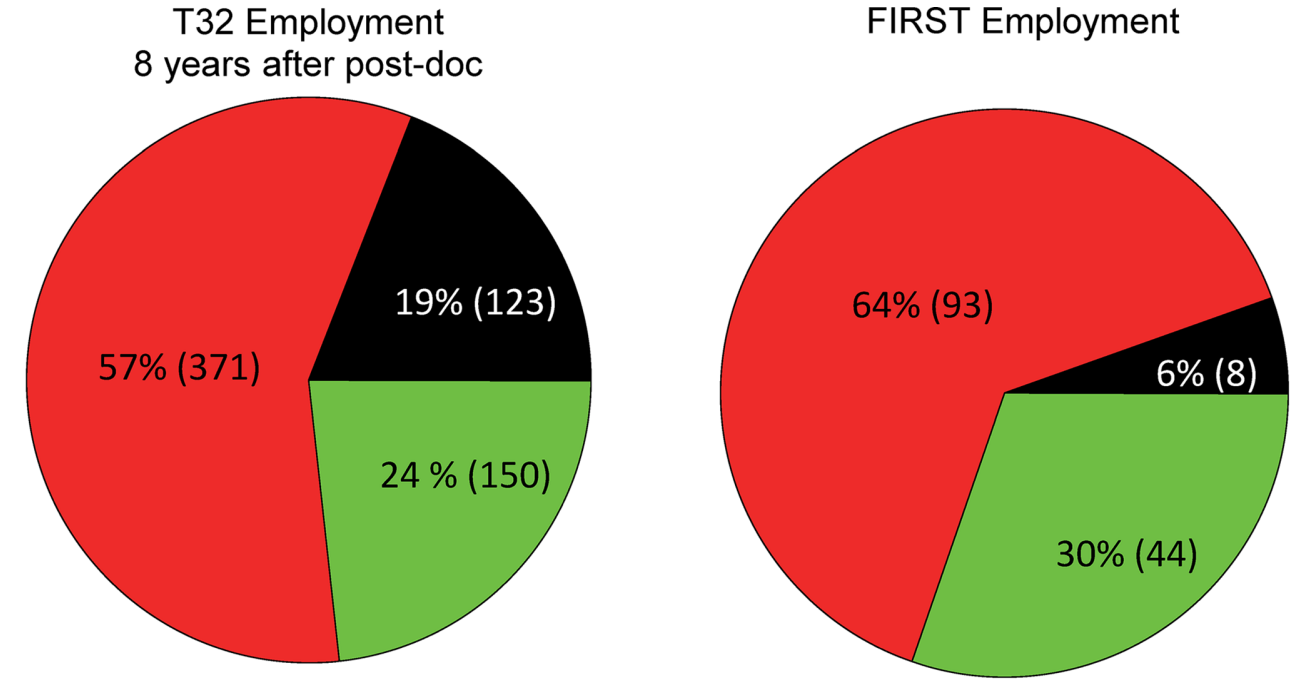

B

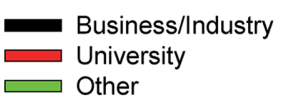

* Other includes self-employed; primary or secondary school; U.S., State, or local government research or administration

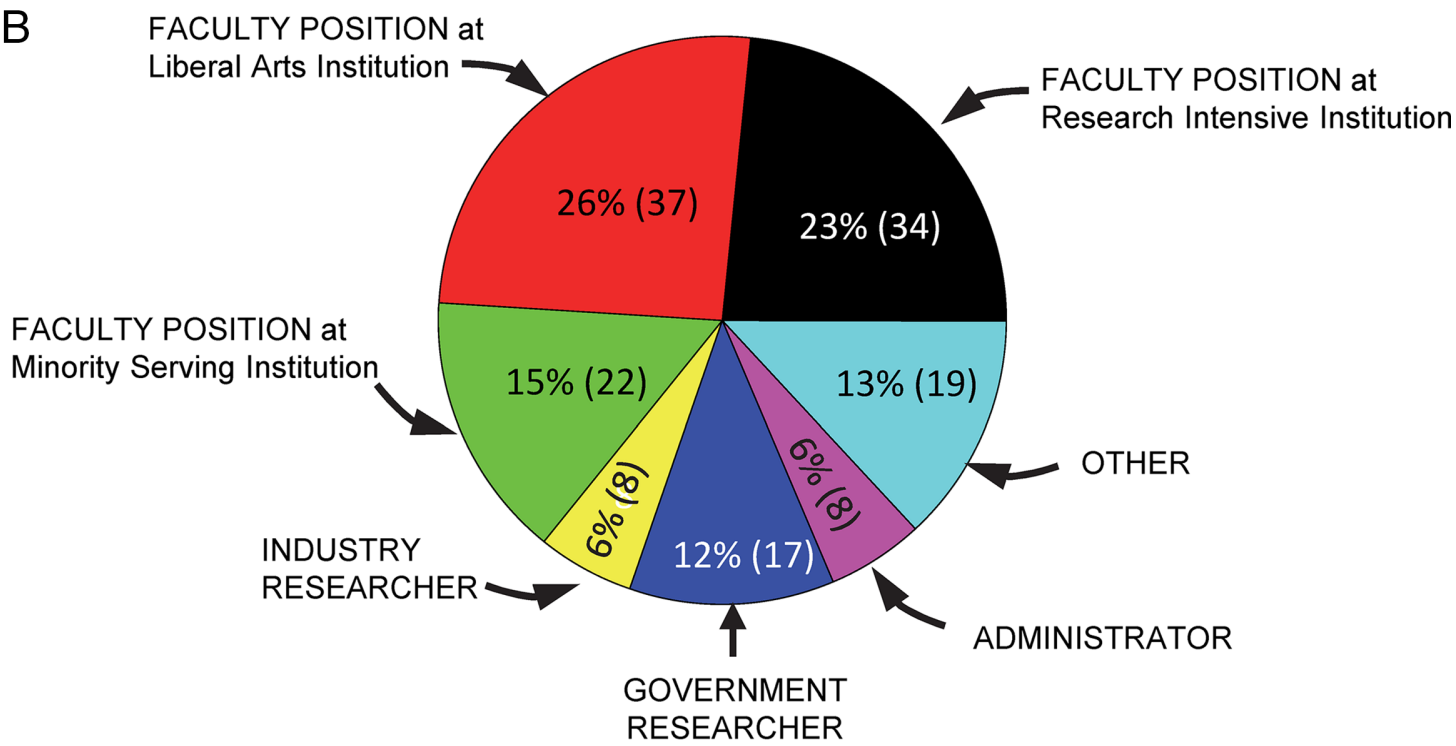

* Other includes self-employed; primary or secondary school teaching, or unknown

FIGURE 2. (A) Employment outcomes for FIRST fellows and national T32 fellows. The employment outcomes of 145 FIRST alumni and 644 former T32 fellows are divided into business/industry (black), university/academic (red), and other (green), including self-employed; primary or secondary school instructors; U.S., state, or local government. (B) Divides the university/academic category and the other category of A into component elements, showing an almost equal division of FIRST faculty into research-intensive, liberal arts, and minority-serving institutions. "Other" includes self-employed and primary or secondary school instructors.

the table and the actual grants awarded to FIRST alumni. FIRST alumni applied for 129 grants, making their success rate $38 \%$. The numbers may be too small to draw definitive conclusions; however, it appears that FIRST alumni are as successful in acquiring grants to support their research as former T32 fellows.

\section{Building Community in a Structured Program of Teaching and Research}

We cannot test hypotheses that might explain FIRST outcomes, because we have not yet identified a comparison group to adequately separate out participant-selection and program-effect 
A

Mean elapsed number of years between last year of T32 support and first NIH competing award for selected NIH grant mechanisms

\begin{tabular}{|c|c|c|c|c|c|c|c|}
\hline \multirow{4}{*}{} & \multirow{3}{*}{ T32 Fellows } & \multicolumn{2}{|c|}{ R01 } & \multicolumn{2}{c|}{ All R Awards } & \multicolumn{2}{c|}{ All K Awards } \\
\cline { 3 - 8 } & Degree & $\#$ & Years & $\#$ & Years & $\#$ & Years \\
\cline { 2 - 8 } & Ph.D. & 2,597 & 5.3 & 2,919 & 4.1 & 20 & 6.1 \\
\hline
\end{tabular}

B.

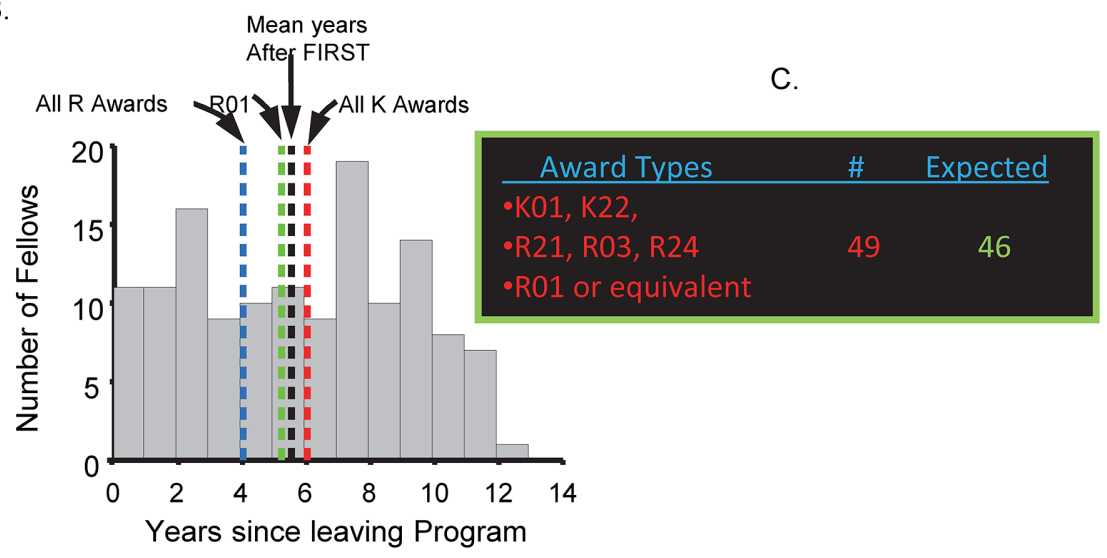

FIGURE 3. FIRST alumni grants. (A) Numerical data available from NIH about the mean time from completing a T32 postdoctoral fellowship until grant awards of various types. (B) Mean times from A are superimposed on the distribution of the number of FIRST fellows who have graduated from the program and remained in academic environments. (C) Based on the mean times and the times after leaving the FIRST program, it is possible to make conservative estimates of the number of grants FIRST fellows are likely to have been awarded to compare with the actual grants awarded. Although the numbers are small, FIRST fellows appear to have met expectations for acquiring grants. R01 equivalents include NSF awards that pay faculty salary and an indirect cost rate the same as a R01. without a program like FIRST that had a community intentionally composed of others who shared their experiences and goals. As noted, the FIRST cohorts or classes have varied over the course of the program, originally having 10 fellows per cohort and currently having six fellows; the program as a whole, then, has had 18-30 fellows at any given time, and the total "FIRST community" includes 177 current and alumni fellows.

Fellows discuss the importance of community in both abstract and concrete ways. They note their FIRST cohort and greater community provide collaboration across scientific disciplines and teaching, camaraderie, fellowship, strong relationships, collegiality, a cohort of peers, and a sense of community:

\begin{abstract}
"[A] major benefit from FIRST was being with a sizable group of other postdocs. We spent a lot of time together discussing teaching, research, the job market, and other aspects of professional development. Several of us traded documents during our first wave of applying for professorships... These have been some of the most important career relationships that I have developed, and they are because of FIRST."
\end{abstract}

biases, which would allow us to posit cause and effect; however, we have built a foundation from which testable hypotheses can emerge. To move toward developing such hypotheses and to further explore FIRST's effectiveness, we surveyed FIRST alumni and performed periodic focus groups with fellows still in their postdoctoral fellowships. The 46 alumni who responded to the survey (30\% response rate) were roughly representative of the total pool of alumni in relation to employment (33\% R1, $31 \%$ liberal arts, $13 \%$ MSI, 9\% administration, $7 \%$ government research, $2 \%$ industry, and $4 \%$ other). In the focus groups and the survey, we asked what the fellows liked best about the program, followed up on responses, and queried alumni on how and whether FIRST helped them achieve their goals.

Virtually all responses had two common themes: 1) the power and importance of the intentional FIRST postdoctoral cohorts and community and 2) the value of the training and mentoring in teaching, especially in conjunction with training in research. Other emergent themes included the opportunity to have an excellent research experience in the lab, to teach and network with an MSI, the chance to obtain leadership and administrative experiences (in organizing conferences or serving on FIRST committees), having independent funding, and gaining confidence and focus in general as a scholar.

\section{Cohort and Community}

Regardless of whether queried during their fellowship, or years afterward, half of all FIRST postdoctoral fellows and alumni consistently report they would not have continued in science at all
These strong feelings and interactions manifest, they say, in a diversity of practical activities and opportunities. FIRST fellows, in addition to having a traditional research mentor, also have a formal teaching mentor, as well as the program director, program administrator, and program teaching coordinator of the program, who all serve as informal mentors:

"I learned from my research mentor and my teaching mentor, but I also learned a lot from my peers. All three were equal in my development, I would say."

More than a dozen FIRST alumni who are now faculty at our partner MSIs have served as teaching mentors for new FIRST fellows, so mentoring weaves across generations of fellows. Fellows report going to job interviews and having FIRST alumni on the search committee; alumni keep current fellows informed of professional opportunities and job openings at their institutions. Fellows mention the effectiveness of having colleagues with similar goals-gaining expertise in research and teaching and entering the academic job market-with whom they share ideas, provide strategies for managing the difficulties of the postdoctoral experience, balance teaching and research, and share and practice all steps of obtaining employment:

"As a scientist I know the importance of going to meetings (weekly lab meetings or international meetings) to develop a network of individuals to bounce ideas off of and present my research. The FIRST cohort of fellows allowed that same setting, 
but instead of my specific field of research it allowed me to discuss student mentoring, teaching and bridging research into teaching. Even the proximity of the cohort was essential to my experience in the fellowship. The opportunity to gather fellows quickly for a practice interview, or to discuss topics for a course was only possible with the large cohort of fellows at Emory during my time."

Fellows emphasize how these positive aspects and power of their FIRST community continued well after they became professionals:

\begin{abstract}
"Many years later, my experiences as a FIRST Fellow still influence my career advancement, beyond a tenured faculty position. As I have moved into full time academic administration, I am valued for my experience as a leader in diversity in higher education, which began with FIRST. I can also call upon the vast network of IRACDA alums, current fellows, and all of their students, colleagues, etc."
\end{abstract}

"Five years in, we shared tips on the tenure process as well as reading each other's materials. I'm sure that in a few years, we'll be reading each other's applications for promotion to Full. I had a much easier, much smoother, and much more productive transition than any of my colleagues at my current institution who started around the same time as I did, and they are all jealous of the connections and support that I still get through my FIRST fellowship."

\section{The Importance of Learning How to Teach}

The value of explicit education and mentored experience in teaching was the second major theme that emerged from surveys and focus groups as one of the greatest benefits of FIRST. Teaching was discussed in a panoply of contexts-including having the opportunity to take a course on teaching techniques in which fellows apply the pedagogies they learned in "teaching" their peers and receiving feedback, while at the same time thinking of teaching as a mode of scholarship analogous to laboratory research:

"Nowhere else in my training have I had any instruction in teaching. The FIRST program had dedicated time for teaching instruction and many opportunities to informally discuss teaching approaches. After completing the FIRST program, I am comfortable and confident discussing and implementing teaching techniques and curriculum changes. The program also introduced me to educational research literature, both as a reader and as a researcher."

Fellows especially value the chance to cultivate relationships with minority students while teaching at least one entire course under the mentorship of a seasoned educator:

"People in the program also helped with establishing a professional network and the program provided information about the best ways to teach. In addition, being part of a cohort of people that valued teaching provided a critical support structure for someone trying to find their niche as an independent scientist."

"I have been able to utilize my talents and skills to better students (many minority) and schools, and I find that to be just as rewarding as furthering our knowledge on basic biological principles."

And FIRST fellows emphasize the importance of the opportunity to mix their intensive teaching experience with rigorous laboratory research in order to learn to balance the two while still postdocs, how these experiences afford them a clear advantage on the job market, regardless of the nature of the job to which they applied:

"I learned to balance teaching and doing research at the same time. Most opportunities for teaching are separate, such that you are either teaching or doing research, but in a faculty job you must be able to do both. Also, starting my tenure-track job with a couple of classes prepped made my transition enormously easier!"

"I went on the market having taught several courses and so was able to make a compelling argument during my interviews that I would have no trouble transitioning to a faculty position where I was expected to teach while maintaining a very active lab, because I was already doing it. Despite interviewing at R1 institutions, I emphasized the teaching component of the fellowship and have since heard that it was a major factor in the decision to hire me... Once I had the job, these same factors were instrumental in helping me get tenure."

"I go up for tenure at a R1 this fall. My students tell me that they learn more in my classes than in those of my peers. The fact that they are learning at all is wonderful! FIRST really helped in time management skills which perhaps is the number one skill for surviving life as a Junior Faculty."

\section{Help in Achieving Career Goals}

When asked directly how FIRST helped them achieve their career goals, in addition to the community and teaching themes, alumni focus on the superb research environment in FIRST, and how it linked to and drove the other strong aspects of the program, such as minority engagement:

\footnotetext{
"I was not sure what I wanted to do, but FIRST helped me see that I wanted to stay in academia and that I felt the best way I could bring minorities into research and medicine would be by having a lab where undergraduates were welcome. Having that vision, I worked hard to build a strong publication track record, work[ed] with undergrads in my lab as a postdoc, and pursued an academic position. Now, I have a lab of graduate students and a technician. Unlike many of the other labs in my department, I am open to undergraduates. I have mentored numerous terrific undergrads, many are minorities, and they have completed their undergraduate Seniors Honor Theses with me, obtained research funding for summer research, and been awarded Academic Excellence Awards at graduation. All six of these undergrads have chosen to stay in medicine and/ or research for the next stage of their careers. Two have been co-authors on manuscripts so far."
}

The financial independence offered by the FIRST fellowship, and how this helps lead fellows to future research funding successes and, ultimately, employment, is also a theme among fellows' comments: 
"The fact that I was self-funded as a postdoc gave me immense freedom, which allowed me to write grants as a postdoc. One of the ones I submitted, an NSF on which I was PI, got funded at the end of my postdoc, and so I started my first faculty position with major federal funding. Obviously this made an enormous difference in my career!"

"Because of my work during my 3-year postdoc I was able to write a successfully funded $\mathrm{K} 01$ from $\mathrm{NIH}$ and obtained a faculty position upon leaving FIRST."

\section{DISCUSSION}

Clearly, American science has a significant challenge-how to develop and maintain a science workforce that is both strong and diverse in the face of a shrinking pool of resources. Recent data and models show that we have successfully begun to respond to the latter by increasing the number of URMs in the science pipeline; however, this has happened without any increase in the proportion of URM professors. And, models suggest, the key point for intervention is increasing the number of URMs who effectively transition from postdoctoral fellowships to the academy (Gibbs et al., 2016). A powerful way to identify best practices in this regard is to analyze existing programs that are successful in developing postdocs-both minority and majority-and transitioning them into the professoriate. The FIRST program is perhaps the largest and longest continuously running science postdoctoral program in the United States, and thus it provides a half-generation's worth of data toward addressing the challenges faced by American science.

\section{Increasing Diversity of the Science Workforce}

FIRST positively affects the diversity of the science workforce. Out of 145 FIRST alumni, nearly all are in science research and teaching positions-64\% are science faculty at universities or 4-year colleges, another $24 \%$ are in science industry or science-related government or administrative jobs, and the remaining $13 \%$ are teaching science in community colleges or K-12 schools. Of these FIRST alumni, 50\% are African American, nearly 25 times the percentage in the national science postdoctoral pool as a whole, and 70\% are women, nearly twice the national percentage (NSF, 2013). FIRST is also diversifying the overall Emory postdoctoral populationthe program increased the number of URM postdocs in biomedical sciences and accounts for an average of 38\% of all Emory URM postdocs over the past 15 years-and the science workforce nationwide, since FIRST alumni teach and research in science at more than 90 institutions and companies in 24 different states and the District of Columbia. Moreover, half of all FIRST fellows report they would not have remained in science at all beyond their $\mathrm{PhD}$ programs without a program like FIRST to provide a community and explicit engagement with both teaching and research in such a supportive environment.

FIRST fellows also help diversify the workforce in other less direct but important ways. Fellows serve as role models during their fellowships by teaching classes at partner MSIs. Thus far, FIRST fellows have developed or revised more than 75 courses at these institutions. In addition, fellows have mentored many MSI undergraduates informally and formally, including 19 in their
Emory research laboratories. FIRST fellows also initiated workshops at our partner MSIs in applying to and attending graduate school; the workshops might be partially responsible for the rise in applications to science $\mathrm{PhD}$ programs from undergraduates at these institutions in the years since the inception of FIRST.

Given the work of FIRST fellows, it is perhaps not surprising that 19 have been hired as faculty at partner MSI institutions (and three more at other MSIs nationwide) over the past half-generation, where they continue to work to diversify the workforce, as do their fellow FIRST alumni who are at majority institutions. In addition, the FIRST alumni at our partner MSIs serve as teaching mentors for the next cohorts of FIRST fellows-with the hope of improving the quality of their experience and thus increasing the likelihood these fellows, too, will be successful in science.

\section{FIRST Fellows Perform at a High Level}

On surveys and in focus groups, many FIRST fellows identify an inherent bias against teaching (vis-à-vis research) in the sciences and in the academy in general, despite the irony that teaching is a major role of most professors. Fellows note the strong positive effect of being in FIRST, an environment where teaching and research are equally encouraged, mentored, and experienced. It may have been in part due to this bias against teaching that, even with strong data demonstrating that FIRST fellows are equally accomplished at the bench as postdoctoral fellows who spend little to no time teaching, early concerns focused on whether the teaching focus of the program might negatively impact fellows' careers by distracting them from research.

Nevertheless, by traditional measures of success for laboratory scientists-peer-reviewed publication rate, employment, and time to funding after that employment-FIRST fellows perform as well (or better) than their research-focused peers. FIRST fellows overall, and fellows from the majority demographic, actually publish more than T32 comparison groups, while URM fellows publish about the same as URMs in the comparison group.

Consistent with national data (NSF, 2013), FIRST and comparison group URM fellows publish less than majority fellows. Depending on the reasons behind this difference, it may be of concern. Gibbs et al. (2014) show that URMs disproportionately drop out of the science career pathway at every stage but that, importantly, this occurs independent of the publication rate of individual scientists. In other words, a URM fellow with a large number of publications is less likely to transition into the professoriate than a majority fellow with the same number of publications. This, as Gibbs and others point out, suggests that the issue of disproportionate attrition may be less related to how many publications URMs have and more related to other, external factors-such as, in "positive" terms, URMs having different priorities for the types of employment they seek and different motivations (e.g., they are more likely to want to give back to their communities), or, in "negative" terms, URMs perhaps feeling discouraged by implicit and explicit racial biases in the system (Gibbs et al., 2014).

To this point, anecdotally, nearly all FIRST fellows not only obtain jobs in science, but obtain their first-choice jobs, often selecting from more than one offer. Fellows have been recruited directly from the FIRST website without their even applying or 
being aware of a job opening. Thus, the more salient point here, in terms of success of FIRST fellows-URMs or not-is that they stay in science as postdocs and then as professors and other science professionals. And they do this in a manner comparable-how many, in what type of jobs-to comparison groups. These data suggest that whatever is different about FIRST and programs like it is better on average for everyone in the program, regardless of gender or demographic, but especially for women and URMs.

\section{Next Steps: How to Best Attract and Retain URMs in Science?}

This question and the practices that underlie it are especially important given recent work suggesting that the key to accomplishing greater representation of URMs in the science professoriate is to improve and smooth the postdoc-to-professor transition (Gibbs et al., 2016).

We have shown that, over the past 17 years, the FIRST program has placed nearly 25 times more African-American PhDs and nearly twice as many women $\mathrm{PhDs}$ in science careers than the national average (NIGMS, 2017). Given that these alumni are still in science, it is not surprising that FIRST fellows also compare favorably with other NIH postdocs in terms of publication rate and then in obtaining funding in their careers. These data have set the stage for developing and testing hypotheses that home in on what makes for a postdoctoral training program that attracts and retains women and URMs.

Preliminary qualitative data obtained from FIRST fellows suggest that one explanation for our results is the program's development of a structured and intentional community-including formal and informal classes; career workshops; and peer, research, and teacher mentoring. Another explanation suggested by our data, which can now be tested, is that providing training and opportunity for teaching increases postdoctoral success.

Intriguingly these two themes-community and teachingare identified as important factors in two recent evaluative analyses of other postdoctoral programs. While these studies did not consider gender or URM engagement specifically, they both demonstrate a positive impact of structured and intentional community, similar to that seen at other educational levels (Brommer and Eisen, 2006; Estrada-Hollenbeck et al., 2011; National Academy of Sciences, National Academy of Engineering, and Institute of Medicine, 2011). Ross et al. (2016) show a significant increase in publication numbers and rates after restructuring of a postdoctoral training program to include developmental training, writing groups, and a more rigorous application process (e.g., requiring agreement from a program faculty member to take on a postdoc before the postdoc can apply) similar to FIRST's. And in qualitative analysis of a National Cancer Institute $\mathrm{K}$ award program, alumni of the program cited specific aspects of that postdoctoral training program-including a structured curriculum and mentorshipas key to their career development, even decades after completing the fellowship (Faupel-Badger et al., 2015).

The theme of community is explicitly or implicitly part of nearly everything fellows say in response to questions about why they like and thrive in FIRST and how the program helps them achieve their goals. Of course, community and support are not only important to FIRST fellows. One of the indirect but important results of FIRST is that other non-FIRST postdocs at
Emory saw how well the FIRST community worked and petitioned the School of Medicine to establish what became one of the first offices of postdoctoral education in the nation. Now this office and FIRST often collaborate on professional development activities for all biomedical postdocs at Emory.

There are many layers of formal and informal support and mentoring within FIRST. Fellows have a research mentor and a teaching mentor; additionally, fellows have a senior FIRST fellow who mentors them, and the FIRST program and teaching directors are also available as mentors, as are many informal peer mentors drawn from FIRST, especially from within fellows' incoming cohorts of six to 10 fellows. Fellows credit this support for everything from attracting them to apply to FIRST in the first place, to assisting them through the challenges of the intense postdoc experience and thus keeping them on the science track, to providing peers who are sounding boards for research and teaching ideas and constructive critics of practice research and job talks, and, following the fellowship, to assisting with promotion and challenges in the jobs they obtain.

Related to their emphasis on cohorts and community support, FIRST fellows report that having a community of scholars that are open to and interested in both teaching and research and seeing the importance of rigorous and integrated training in both makes a big difference. Fellows attribute much of the success of the program-their remaining in science, their success in the job market and in the jobs they secure-to this explicit combined training they receive in FIRST. Notably, FIRST alumni report this regardless of the nature of their employment; unsolicited, fellows in R1 institutions or in industry go out of their way, for example, to comment that training in teaching together with training in research both helped them get their jobs and smoothed and improved the transition into those jobs so that they could be successful.

In addition to community and teaching/research training, other themes that emerge from surveys and focus groups as contributing to fellows' perceived success include the independence and freedom from funding concerns and the opportunities for leadership the fellowship allows.

\section{LIMITATIONS}

The major limitation of this analysis is the lack of comparison groups that would allow us to test for cause and effect of the different aspects of the FIRST program. While we are able to compare a number of important aspects of postdoc successpublication rate, jobs obtained, and funding after obtaining jobs-we have not yet identified a comparison group to control for program and participant effects. Without access to such a group, several important questions about shaping effective postdoc training programs cannot be addressed. The comparison group data we do have from T32 programs-from one NIH institute (NIGMS) and all on basic science postdocs with PhD's-are not ideal, because these are collated data from many T32 fellows in a diversity of programs that have different requirements, recruitment strategies, and training, depending on which academic institution was hosting them. Also, although we analyze data from a large number of fellows over many years, we nevertheless are assessing data from a single program; thus, extrapolation of findings to other environments should be done carefully. 
Until relatively recently, such as in the work noted earlier (Faupel-Badger et al., 2015; Ross et al., 2016), analysis of postdoctoral fellows and their experiences has been minimal (Sigma $\mathrm{Xi}, 2005$; NIH, 2012) and, related, we know more about and keep more careful track of FIRST fellows than institutions do typically with their postdocs. Ironically, such challenges are related to the very reasons programs like FIRST are needed in the first place.

\section{SUMMARY}

To stay at the top, American science is in serious need of effective postdoctoral programs that prepare everyone-men, women, majority populations, and URMs-for a successful transition into academia. It is vital to identify and disseminate best practices in this regard. Over half a generation, FIRST has developed a model for just such a postdoctoral training program, one that creates an intensive and diverse, cohort-based community of scholars who gain expertise simultaneously in research and teaching. FIRST is nationally known as a resource for identifying excellent faculty: fellows have been invited to interview and hired for unadvertised positions simply because they were in FIRST.

We now have many of the pieces of the puzzle: 1) the number of URM PhDs has increased ninefold, but the number of URM professors has stayed the same or decreased; thus, the postdoctoral stage is key; 2) virtually all URM (and women) FIRST alumni are still in science, and many are in academia; 3) extensive research demonstrates the effectiveness of intentional community building for successful educational programs, especially for women and URMs; and 4) FIRST fellows and alumni emphasize the important role community plays in their postdoctoral experience and following careers. And so, FIRST represents one model we can continue to study to determine if (and, if so, how well) these pieces connect, and how best to develop strategies for effective postdoc-to-academia transitions for women, URMs, and all fellows.

\section{ACKNOWLEDGMENTS}

We acknowledge Beverly Medley for her tireless work as FIRST administrator every year the program has been in existence. We also thank Drew Kohlhurst for his assistance with program evaluation using focus groups and Maggie Mang for her analysis of qualitative data. We are grateful for our support from the NIH's IRACDA program these 18 years (currently grant NIGMS K12 GM000680).

\section{REFERENCES}

Alberts, A., Kirschner, M. W., Tilghman, S., \& Varmus, H. (2014). Rescuing US biomedical research from its systemic flaws. Proceedings of the National Academy of Sciences USA, 111(16), 5773-4777. doi: 10.1073/ pnas.1404402111

Bashara, C. (2002). The last word: The impact of PFF on new and future faculty. Liberal Education, 88(3), 54-59.

Brommer, C. L., \& Eisen, A. (2006). FIRST: A model for increasing quality minority participation in the sciences from the undergraduate to the professoriate level. Journal of Women and Minorities in Science and Engineering, 12(1), 35-46. doi: 10.1615/JWomenMinorScienEng.v12. i1.30

Estrada-Hollenbeck, M., Woodcock, A., Hernandez, P. R., \& Schultz, P. W. (2011). Toward a model of social influence that explains minority student integration into the scientific community. Journal of Educational Psychology, 103(1), 206-222. doi: 10.1037/a0020743

Faupel-Badger, J. M., Baue, K., Nelson, D. E., \& Tsakraklides, S. (2015). Alumn perspectives on career preparation during a postdoctoral training program: A qualitative study. CBE-Life Sciences Education, 14(1), ar1. doi: 10.1187/cbe.14-06-0102

Gibbs, K. D., Basson, J., Xierali, I. M., \& Broniatowski, D. A. (2016). Decoupling of the minority PhD talent pool and assistant professor hiring in medical school basic science departments in the US. eLife, 17, 5. doi: 10.7554/ elife. 21393

Gibbs, K. D., McGready, J., Bennett, J. C., \& Griffin, K. (2014). Biomedical science Ph.D. career interest patterns by race/ethnicity and gender. PLoS ONE, 9(12), e114736. doi: 10.1371/journal.pone.0114736

Holtzclaw, J. D., Eisen, A., Penumetcha, M., Whitney, E., \& Kimbro, S. (2006) Teaching bioinformatics at a minority institution. Cell Biology Education 5, 52-64.

Holtzclaw, J. D., Morris, L. G., Pyatt, R., Giver, C. S., Hoey, J., Haynes. , ... Eisen, A. (2005). FIRST: A model for developing new science faculty. Journal of College Science Teaching, 34, 24-29.

Hue, G., Sales, J., Comeau, Dawn, Lynn, D. G., \& Eisen, A. (2010). The American science pipeline: Sustaining innovation in a time of economic crisis. CBELife Sciences Education, 9(4), 431-434. doi: 10.1187/cbe.09-12-0091.

Jackson, M. C., Galvez, G., Landa, I., Buonora, P., \& Thoman, D. B. (2016) Science that matters: The importance of a cultural connection in underrepresented students' science pursuit. CBE-Life Sciences Education, 15(3), ar42. doi: 10.1187/cbe.16-01-0067

Keen-Rhinehart, E., Eisen, A., Eaton, D., \& McCormack, K. (2009). Interactive methods for teaching action potentials, an example of teaching innovation from neuroscience postdoctoral fellows in the Fellowships in Research and Teaching (FIRST) program. Journal of Undergraduate Neuroscience Education, 7(2), A74-A79.

Krishnamoorthy, K., \& Thomson, J. (2004). A more powerful test for comparing two Poisson means. Journal of Statistical Planning and Inference, 119, 23-35.

Layton, R. L., Brandt, P. D., Freeman, A. M., Harrell, J. R., Hall, J. D., \& Sinche, M. (2016). Diversity exiting the academy: Influential factors for the caree choice of well-represented and underrepresented minority scientists. CBE-Life Sciences Education, 15(3), ar41. doi: 10.1187/cbe.16-01-0066

Mantovani, R., Look, M. V., \& Wuerker, E. (2006). The career achievements of National Research Service Award postdoctoral trainees and fellows: 1975-2004. Bethesda, MD: ORC Macro.

Merriam, S. B., \& Tisdell, E. J. (2016). Qualitative research: A guide to design and implementation. San Francisco: Jossey-Bass.

National Academy of Sciences, National Academy of Engineering, and Institute of Medicine. (2011). Expanding underrepresented minority participation: America's science and technology talent at the crossroads. Washington, DC: National Academies Press

National Institute of General Medical Sciences. (2017). IRACDA participating institutions. Retrieved March 10, 2017, from www.nigms.nih.gov/training/ careerdev/pages/PartInstIRACDA.aspx

National Institutes of Health. (2012). Biomedical research workforce working group report. Retrieved March 10, 2017, from https://acd.od.nih.gov/ biomedical_research_wgreport.pdf

National Science Foundation. (2013). National Center for Science and Engineering Statistics Survey of doctorate recipients. Retrieved March 10, 2017, from www.nsf.gov/statistics/2017/nsf17310/static/data/tab9-22.pdf

Ross, R. G., Greco-Sanders, L., \& Laudenslager, M. (2016). An institutional postdoctoral research training program: Increasing productivity of postdoctoral trainees. Academic Psychiatry, 40(2). doi: 10.1007/s40596-015-0281-5

Rybarczyk, B. J., Lerea, L., Whittington, D., \& Dykstra, L. (2016). Analysis of postdoctoral training outcomes that broaden participation in science careers CBE-Life Sciences Education, 15(3), ar33. doi: 10.1187/cbe.16-01-0032

Sigma Xi. (2005). Doctors without orders. Retrieved March 10, 2107, from www.sigmaxi.org/docs/default-source/Publications-Documents/ postdoc-survey-highlights.pdf?sfvrsn=2

Thompson, N. L., \& Campbell, A. G. (2013). Addressing the challenge of diversity in the graduate ranks: Good practices yield good outcomes. CBE-Life Sciences Education, 12(1), 19-29. doi: 10.1187/cbe.12-04-0054 